\title{
Sociological Analysis of Police Training Practices in Ghana: Theoretical and Conceptual Schools of Thought
}

\author{
Ronald Osei Mensah \\ M.Phil. Graduate, Department of Sociology and Anthropology, University of Cape Coast
}

\begin{abstract}
The purpose of this paper is to critically look at the theoretical and conceptual schools of thought of Talcott Parsons AGIL theory in relation to police training practices. It is realized that Parsons AGIL theory has a significant relation and application to police training practices. The researcher in related studies looked critically at the AGIL theory in relation to the curriculum, scope of training and the pedagogical practices employed by police training academies (A), the social outcomes of police training practices $(\mathrm{G})$, how the police apply their training to police work (I) and the challenges facing police training academies (L). It has therefore being established that the resources used in the police training academies like the curriculum, the equipment and pedagogical materials in achieving appropriate goals is termed as Adaptation. In addition how the police can fulfill and achieve their core mandates would basically be referred to as Goal Attainment in the context of this study whereas the various divisions in the police service that come together to achieve their core mandates is referred to as Integration and lastly the risk, stresses and challenges police personnel go through in the course of delivering their duties can simply be referred to as Latency. It is therefore recommended by the researcher that various resources (A), various divisions in the police service should work in harmony (I) to achieve prescribed goals (G) effectively and efficiently and minimizing associated challenges and risks $(\mathrm{L})$ the police face in their work delivery.
\end{abstract}

Keywords: sociological, police, training practices, AGIL

DOI: $10.7176 /$ RHSS/9-12-15

Publication date: June $30^{\text {th }} 2019$

\section{Introduction}

The training of employees at all levels within organization is now considered a vital component in maintaining competitiveness in the international arena. It is also of some significance within the human resource management (HRM) and human resource development (HRD) literature. If one accepts a competitive market perspective on HRM or development then a central notion is the view that training, development and education strategies are key meanings by which the inefficiencies of the employment relationship can be reduced and a closer approximation to competitive labour market outcome attained. At the level of the firm, these activities provide a means by which a number of key organizational goals can be achieved. Some of the most common outcomes cited in the literature include quality, employee empowerment, teamwork and multi-skilling (Metcalf, Walling and Fogarty, 1994 as cited in Anane-Appiah Sampson, 2011).

Training serves to help increase upward mobility within the organization, to adjust workers to the technological changes affecting the workplace, and often simply to introduce place to the world of work at the entry level. The advantages of organizational training activities may extend throughout a person's entire career and may help develop the individual for future responsibilities. Training, then involves the development of the person's knowledge, skills and attitude. It is a person's resource developmental activity that is closely related to increase or maintaining the productivity of employees (Asare-Bediako, 2002 as cited in Mensah, 2017).

However, deficiencies tend to constrain training and development activities. As Currie (2004) points out, the various levels of evaluation - reactions, learning, job behaviour, organizational unit and ultimate value - act as power links in a chain of cause and effect. Training leads to reactions; which lead to learn, which leads to changes in job behaviour; which lead to changes in the organizational unit; which lead to changes in the achievement of the ultimate goals of the organization.

Staff development policies in Ghana Police Service seek to ensure that staff are systematically trained, retrained and developed in order to equip them with knowledge; skills and competence that are required for effective training delivery and monitoring. It is evident that the central government and the private business sector have committed and continues to commit funds into training and development; it is worth finding out if the resources invested in this endeavour are adequately rewarded. In the light of these benefits that this study seeks to do a sociological analysis of police training practices in Ghana using Talcott Parsons AGIL taxonomy of Adaptation, Goal Attainment, Integration and Latency.

\section{Statement of the problem}

The discussion above focuses on one thing. To make a sociological analysis of police training practices in Ghana focusing on theory and concept using Talcott Parsons AGIL taxonomy. In recent times, it is evident that training at the police training academies is problematic (Corston, 2007). Programmes are not taught in appropriate ways. 
For example, police accountability is taught as theory but its practical application is not discussed and all of these have to deal with the curriculum of police training academies. It has been revealed that most members of the police organisation do not even have access to basic documents, such as the Constitution, the Police Service Act or the Police Service Instructions (Corston, 2007) (Adaptation). A huge component of complaints to the Commission for Human Rights and Administrative Justice (CHRAJ) deal with Police misconduct. Reforming those institutions without corresponding review in the curriculum, scope of training and its pedagogy through relevant training will be very sub-optimal (Atuguba, 2007).

Pokoo-Aikins (2009) has revealed that there a lot challenges facing the police training schools of which some are lack of proper equipment, logistics and training materials, lack of motivation, low level of technology, among others. In addition, there are stresses officers go through in the course of delivering their duties. The problem existing currently within the Ghana Police Service (GPS) is indulgence in bribery and corruption, poor delivery of operations, no response or delay in response to crime, lack of professionalism, among others (Osei, 2008) (Latency). Therefore this paper is looking at how the police institution can bring together all the various departments and units in the service (Integration) to work cohesively to achieve organizational goals and objectives (Goal Attainment).

There is therefore the need for a critical sociological analysis of the AGIL theory or taxonomy to see how it affects police curriculum, the application of police training practices, the challenges and stresses of policemen and women and the goals or social outcomes of police training practices.

\section{Significance of the paper}

The findings of this study would be relevant to researchers, police officers, especially the instructors at the various police training schools in Ghana, trainees and administrators in the various police training schools in Ghana. The recommendations of the study will be of relevant use to the Ghana Police Service (GPS) and the various police training schools across the country. Also, the outcome and recommendations of this study will add to the existing knowledge on training practices and effectively address the problems facing the training academies and the police service in general. The study finally serves as a source of theoretical and conceptual literature to any individual or institution for the purpose of further research on the subject or other related areas.

\section{Literature Review}

\subsection{History of Policing in Ghana}

The Ghana Police Service is organized at national level and has a unitary command structure under the Inspector General of Police (IGP). Although there are many regional and divisional commands, they all report to the National Headquarters in Accra (Library of Congress Country Studies, 1994). The origin of Ghana police force lies in efforts by the British council of merchants to protect trading routes and depots. In 1830, the council hired numerous guards and escorts. Fourteen years later, the British established the 120-member Gold Coast Militia and Police (GCMP). The authorities disbanded this force in 1860 and created a ninety-member corps called the Queen's Messengers. Military units assumed the GCMP's paramilitary duties (Library of Congress Country Studies, 1994).

The force became the "Gold Coast Constabulary" in 1876. The Police Ordinance, passed in 1894, gave legal backing to the formation of a civilian police force in the colony. During the Asante wars, the Queen's Messengers joined the Hausa Constabulary, imported from Nigeria, and formed the Gold Coast Armed Police Force. In 1876, the British reorganized this unit into the Gold Coast Constabulary, which was divided into two forces in 1901, with the paramilitary mission assigned to the Gold Coast Regiment and the police functions given to the Gold Coast Police Force. By 1902, the police had been divided into General, Escort, Mines and Railway Police and this was legalized by the Police [Amendment] Ordinance of 1904. The Northern Territories Constabulary, which the British created in 1907, joined the Gold Coast Police Force shortly after World War I. This left Ghana with one police force, a situation that prevailed until independence. A Marine Police unit was formed in 1906 but was replaced by the Customs, Excise and Preventive Service (CEPS) in 1942 (Pokoo -Aikins 2009).

The organisation of the service first started during the $1950 \mathrm{~s}$, when the British instituted several changes in the Gold Coast Police Service to modernize, enlarge and better equip the police. The greater importance was the decision by Britain to Africanize the police. Initially they had restricted access to senior positions in all branches of colonial administration, but following the agitation which erupted after the three ex-servicemen, Sergeant Adjetey, Corporal Attipoe and Private Odartey Lamptey, who were killed in 1948 by the colonial police, while leading a peaceful march to the Osu Castle to present a petition to the then Governor of the Gold Coast, this trend was gradually reversed.

In 1951, for example, 64 of the 80 senior police officers were foreigners but by 1958 only 11 of these senior officers were of foreign origin (Duah, 1995). The first Ghanaian Police Commissioner was Mr. E.R.T Madjitey who was appointed on October 9, 1958. By the early 1960s, the only expatriates who remained on the force were a few technical advisers and instructors. Nkrumah, however, distrusted the police. After an unsuccessful assassination attempt against Nkrumah in 1964 by a police constable, he disarmed the police, discharged nine 
senior officers, detained eight others, and removed the Border Guards unit from the police and placed it under military control. Nkrumah also reduced the size of the police force from 13,247 to 10,709 in 1965 (Library of Congress Country Studies, 1994).

After the demise of the Nkrumah regime, the size of the police force was increased by the sitting Governors Lt. Gen. Joseph Ankrah and Lt. Gen. A. A. Afrifa from 17,692 to 19,895 in 1968. The government also restored the Border Guards unit to police control in 1972. This unit again became an autonomous unit. By the early 1980s, the police enjoyed respect from most Ghanaians because, for the most part of these years, they were not involved with government attempts to suppress political dissidents or to punish those suspected of trying to overthrow the Rawlings regime, those duties were normally assigned to the armed forces (Winslow, 2011).

In 1993 under the fourth republic of Flt.Lt. Jerry John Rawlings, Ghana's police establishment consisted of 351 police officers, 649 inspectors, and 15,191 personnel in other ranks distributed among 479 stations. An eightmember Police Council, established in 1969, advises the inspector general on all personnel and policy matters. The inspector general supervises twelve police regions, each commanded by a Deputy or Assistant Commissioner of Police (DCOP/ACOP). The police regions in turn are divided into districts, stations, and posts. The Police Service is composed of General Administration, Criminal Investigations Department (CID), to which Domestic Violence and Victim Support Unit (DOVVSU) are attached, operations department and communication department.

Recruitment into the police is conducted at the rank-and-file and the commissioned-officer levels. All recruits must be between eighteen and twenty-five years of age and graduates between twenty-six and thirty-five years and must pass a medical examination, with no criminal record. Escort Police applicants must have at least basic knowledge in spoken English. General Police applicants must have completed middle school or Junior High School or Senior High School, and officer corps applicants must hold a University Degree or Higher National Diploma. Training for rank-and-file personnel in the Escort and the General Police forces is conducted at the Elmina police depot; now Winneba and the other police training schools located in Accra, Kumasi, Ho, Koforidua and Pwalugu. Since 1975, recruits have attended a nine-month course of instruction in physical training and drill, firearms use, unarmed combat, and first aid. Escort police are given general education and instruction in patrol and escort duties. General police is trained in criminal law and procedures, methods of investigation, current affairs, social sciences and police duties (Pokoo-Aikins, 2009).

The Ghana Police College, established in 1959, offers a nine month officer cadet course and two- to six-week refresher courses in general and technical subjects. At the Police Command and Staff College; guest lecturers come from the police headquarters, security agencies, institutions of higher learning like the universities and other institutions in Ghana. The officer cadet course offers instruction in criminal law and procedures, laws of evidence, police administration, finance, social sciences, practical police work, and physical fitness.

Upon graduation, cadets are sworn in and promoted to assistant superintendent (Ghana Police Service, 2011). Since the early 1990s, the reputation of the police has improved, because, an increasing number of police have been deployed overseas to support Ghana's commitment to international peacekeeping operations. In 1992-93, for example, a police contingent served with the United Nations Transitional Authority in Cambodia. In addition to supervising local police and maintaining law and order, this contingent also tried to prevent gross violations of human rights and fundamental freedoms (Library of Congress Country Studies, 1994).

Public confidence in the police remains low, and mobs have attacked several police stations due to perceived police inaction, as delay in prosecuting suspects, rumors of collaboration with criminals, and the desire of the public to deal with suspects through instant justice (US Department of State, 2004).

In view of all these, the study aimed to make a sociological analysis of police training practices in Ghana with the help of Talcott Parsons AGIL Taxonomy.

\subsection{Concept of Training}

Adarkwa (2001) refers to training as a planned activity that aims at fulfilling challenges in the individual or group of people concerning their knowledge, skilled and committed employees. According to De Silva (1997), training is the transferring of information and knowledge to employees. He also stressed that training should be considered along with education policies and systems which are crucial to the development of human resources in an organization. From the above explanations, it is imperative for the police to have a well-defined and structured curriculum which would be used in the process of training and learning by adapting the needed resources like police books and other gadgets used for training in order to achieve stated goals and objectives.

Certo (2003) also emphasized that after recruitment and selection, the next step is providing appropriate human resources for the organization in training. Training is the process of developing certain qualities in human resources that will help them to be more productive and contribute towards organizational goal and the attainment of such goals. When police are trained very well, they become more productive in the service and that helps them to achieve their goals successfully without any sort of hindrance or fear.

Also, Cole (2000) indicated that training is usually preparation for an occupation or for specific skills. It is 
job oriented rather than personal. Meaning, training is directed towards a specific goal or purpose. BissoondoyalBheenick, Brooks and Yip (2006), look at training as critical to total quality management efforts, because the personnel at many times need to be taught how to do things differently from the way they did things in the past.

According to De Cieri and Kramar (2003), training refers to a planned effort by a company to facilitate employees learning of job related abilities. These abilities include knowledge, skills or behaviours that are significant for successful job performance. Almost all institutions in Ghana have started to recognize the important role that training plays in improving productivity, quality and competitiveness. It is widely accepted that people in the security service go through some form of training before they are employed to work in the service. Fleck and Kraemer (2004) demonstrated that training has a positive impact for the individual and the organization.

From the above, it can be deduced that, some are of the view that training are the opportunities that will be available for the knowledge and skills to perform a specific activity to be acquired whereas others are also of the view that training is the way of improving trainee skills for better on-the-job performance. Salas, Cooke and Rosen, (1992) are also of the view that training is a systematic acquisition of knowledge of what we think, the skills that is what we do and attitudes. Others also see training as improving trainees' skills to the point where he or she can do the job more effectively. Training is also seen by other authors as transfer of information and knowledge to trainees, whereas others are of the view that it is an ongoing process of helping trainees perform a particular work from the day they start work.

From the above, it is realized that most authors have a common idea as to what training is or entails. From the discussion, it can be deduced that training is a systematic process whereby knowledge, skills and all other resources are used to equip people in order to perform better on the job.

In the context of this study, training will be conceptualized as an ongoing process of helping employees perform a particular work from the day they start work. By so doing, effective assessment of police training is designed to improve a person's skills and competences to do a particular job or accomplish a task. Therefore, when training is rigorously done and taken serious, then the goals of the police service or institution would be achieved appropriately.

\subsection{Theoretical Framework}

The framework of the study used the AGIL taxonomy of Adaptation, Goal attainment, Integration, and Latent Pattern maintenance by Talcott Parsons (1951) as cited in Schwartz (2012). The AGIL paradigm is a systematic depiction of certain societal functions, which every society must be able to employ in order to maintain a stable social life.

In this study, assessment of police training practices can be attained by meeting the needs defined by the AGIL taxonomy - adaptation, goal attainment, integration, and latent pattern maintenance (Mensah, 2017).

First of all is Adaptation. According to Parsons (1951 as cited in Schwartz, 2012) adaptation involves securing sufficient resources from the environment and then distributing these throughout the system. Relating this to police training, adaptation refers to the need to get adequate knowledge (resources) in informing police training practices. The knowledge mobilized through the adaptive use of the resources is then utilized in ensuring specific goals attainment within the police service.

Second is Goal attainment. This refers to establishing priorities among system goals and mobilizing system resources for their attainment or the need for all societies to set goals towards which activity is directed (Parsons, 1951 as cited in Schwartz, 2012). At the level of the social system, the requirement of goal attainment is typically met by the polity, as it is the realm in which goals are prioritized, and discrepancies are resolved between "the inertial tendencies of the system and its 'needs' resulting from interchange with the situation" (Parsons 1961:41) as cited in (Schwartz, 2012). The polity and the government establish status and reward systems so that social goals can be attained. In the context of this study, goal attainment relates to how police officers can achieve their set goals appropriately without any challenge or disruption. Goals must be set and those goals must be prioritized and achieved through effective police training.

In applying this to the study or police training, Act 350 of the Ghana Police Service instructions defines clearly some core mandates or functions of the service which are; the protection of life and property, prevention and detection of crime, apprehension and prosecution of offenders, preservation of peace and good order and enforcement of all laws, Acts, decrees with which it is directly charged. When all these are achieved effectively and applied well then we can say police training practices has been efficient.

The third paradigm is Integration. Integration refers to the coordination of a system's or subsystem's constituents parts, since "all social systems are differentiated and segmented into relatively independent units" (Parsons 1961) as cited in (Garriga \& Melé 2004) or a system whereby all the adaptive efforts of social institutions within a society needs to be integrated into a cohesive system (Parsons, 1951). Within the four systems of action (behavioural organism, personality, social system and cultural system), the function of integration is met primarily by the social system. With regard to this study integration sees to how trainees incorporate whatever they have learnt into practice. That is, the various divisions and departments within the Ghana Police Service need to be 
regulated so that a harmonious society can emerge from their interaction.

In applying this to police training, the various divisions in the police service like the Criminal Investigation Department (CID), Highway Patrol Unit (HPU), the Motor Traffic and Transport Department (MTTD), Domestic Violence and Victim Support Unit (DOVVSU) and many other departments within the service should come together and work unanimously by putting whatever has been taught by their instructors into good and effective use and in the end expected results from police training practices would be achieved.

The last but not least is Latency or Latent pattern maintenance (L). This refers to the "imperative of maintaining the stability of the patterns of institutionalized culture". This function is carried out primarily by the cultural system, as it is through culture (made up of shared meanings and values) that specific patterns of behaviour are maintained (Parsons 1961). This, therefore, pertains to the risks, challenges and stresses police officers pass through when delivering their duties.

Here, it embraces two related problems: pattern maintenance and tension management. Pattern maintenance pertains to how to ensure that actors in the social system display the appropriate characteristics in terms of motives, needs and role-playing whereas tension management concerns dealing with the internal tensions and strains of actors in the social system. In applying this to the study, it basically looks at the challenges, stresses and risks police officers face in the course of delivering their duties.

All these challenges can be minimized in the form of social learning when police officers are sufficiently motivated to play their part within the police service. Therefore, the challenges, stresses and risks police officers face will be minimized within the system of latent pattern maintenance.

\subsection{Relevance of the Theory to the Study}

The four functions of AGIL are classified into external, internal and consummatory problems. External problems involve the use of natural resources (adaptation) and making decisions to achieve goals (goal attainment), whereas keeping the community integrated (integration) and maintaining the common values and practices over succeeding generations (latency) are considered internal problems.

The functions of the AGIL taxonomy in relation to this study are depicted in Table 1 below;

Table 1 : Functions of the AGIL Taxonomy

\begin{tabular}{|c|c|c|}
\hline & Instrumental functions & Consummatory functions \\
\hline \multirow[t]{2}{*}{ External problems } & Adaptation & Goal attainment \\
\hline & $\begin{array}{l}\text {-the knowledge received through } \\
\text { adaptive use of resources }\end{array}$ & $\begin{array}{l}\text { - How the police service } \\
\text { can achieve their core and } \\
\text { other functions } \\
\text { effectively }\end{array}$ \\
\hline \multirow[t]{2}{*}{ Internal problems } & Latency (or Pattern Maintenance) & Integration \\
\hline & $\begin{array}{l}\text {-The challenges, stresses and risks } \\
\text { police officers go through in the } \\
\text { course of delivering their duties }\end{array}$ & $\begin{array}{l}\text { How police officers put } \\
\text { into practice whatever } \\
\text { they have been taught }\end{array}$ \\
\hline
\end{tabular}

Source: Parson (1951)

Each of the four individual functional necessities is further divided into four sub-categories. The four subcategories are the same four functions as the major four AGIL categories. In this way, citizenship (or civil society) represents, according to Parsons, the goal-attainment function within the subsystem of the societal community. For example, a community's adaption to the economic environment might consist of the basic "industrial" process of production (adaption), political-strategic goals for production (goal-attainment), the interaction between the economic system and the societal community, which integrates production mechanisms both in regard to economic as well as societal factors (integration), and common cultural values in their "selective" relevance for the societaleconomic interchange process (Latency or Pattern Maintenance). According to Parsons (1951), all social or action systems have four major needs - adaptation, goal attainment, integration, and latent pattern maintenance. How these needs are met determines the success of any social system.

First of all is Adaptation. That is the knowledge mobilized through the adaptive use of resources by trainees by knowing the curriculum of police training schools. That is, the knowledge trainees acquire as part of their training. This will help the trainees to learn all the dos and don'ts of the service and know when to apply them appropriately. This will go a long way to produce good and law-abiding officers into the police service hence effectiveness and efficiency.

With Goal Attainment, the police ensure how set goals are achieved properly and effectively without any hindrances of any sort. So after trainees are trained in the police academies, they are expected by the society to deliver and work effectively to expectation in order to achieve set goals or the core mandates of the service. As aforementioned, Act 350 of the police service instructions, define clearly some core mandates or functions of the service which are; the protection of life and property, prevention and detection of crime, apprehension and prosecution of offenders, preservation of peace and good order, and enforcement of all laws, Acts, decrees with 
which it is directly charged. In all, when all these core mandates of the police service as enshrined in Act 350 are effectively achieved then we can say that they have attained their goals effectively. In addition, if goals are attained properly and effectively by the police service, it helps to reduce a lot of social vices in our various institutions, be it the political institution, religious institution, the economy institution, marriage institution, education institution, health institution as well as the mass media.

Third is Integration. The various divisions and departments within the Ghana Police Service need to be regulated so that a harmonious society can emerge from their interaction. In applying this to police training practices, integration here means how police personnel or trainees can put whatever they were taught at the training academies into good, effective and practicable use. This is by applying what they were taught at the academies on the field. By so doing, a lot of societal problems and disorders we face in our society will be minimized.

Last of all is Latency. Latency here involves two main things and these are Pattern maintenance and Tension management. Pattern maintenance means establishing proper roles and motives or how to ensure that actors in the social system display the appropriate characteristics in terms of motives, needs and role-playing whereas tension management involves dealing with internal tensions and strains of actors in the social system.

In relation to this study, latency here means the challenges, risks and stresses police officers go through in the course of their day to day duties. For example, the police are being tagged as being corrupt, as being bribed, brutalizing, insubordinate and many other vices that tarnish the image of the police service. These are some of the challenges or problems police officers face.

On the other hand, when these tensions, stresses, risks facing police officers are curtailed or minimized then we are dealing with the internal tensions and the strains of actors in the social system. That is how we can feasibly address the challenges facing police officers appropriately.

\subsection{Conceptual Framework}

The conceptual framework of the study is based on focus of the study by doing a sociological analysis of police training practices in Ghana and relating it to the AGIL taxonomy of adaptation, goal attainment, integration and latency (Parsons, 1951). Adaptation here clearly talks about the curriculum, the scope of training and the pedagogical practices of police training whereas goal attainment also talks about the outcomes or results emanated from police training practices. Integration also clearly brings out how well police can apply their training to police work. In the course of application of training to police work they face some challenges, stresses and risks thus latent pattern maintenance.

The conceptual framework also brings out the challenges facing the training academies. Some of the challenges identified form literature were inadequate learning materials, lack of training needs, inadequate scenario rooms, poor work accountability, lack of systematic and comprehensive training and need analysis, lack of funds to implement Human Resource Development policies, failure to evaluate the effectiveness of training and development programmes more rigorously among others. The framework further depicts the effectiveness of the training practices in terms of work ethics, control tactics, defensive training, traffic enforcement, accountability and many others.

The relevance of the conceptual framework is to bring out focus of the study and how to conceptualize it. Figure 1 below depicts the conceptual framework for the study. 


\section{CONCEPTUAL FRAMEWORK FOR POLICE TRAINING PRACTICES}

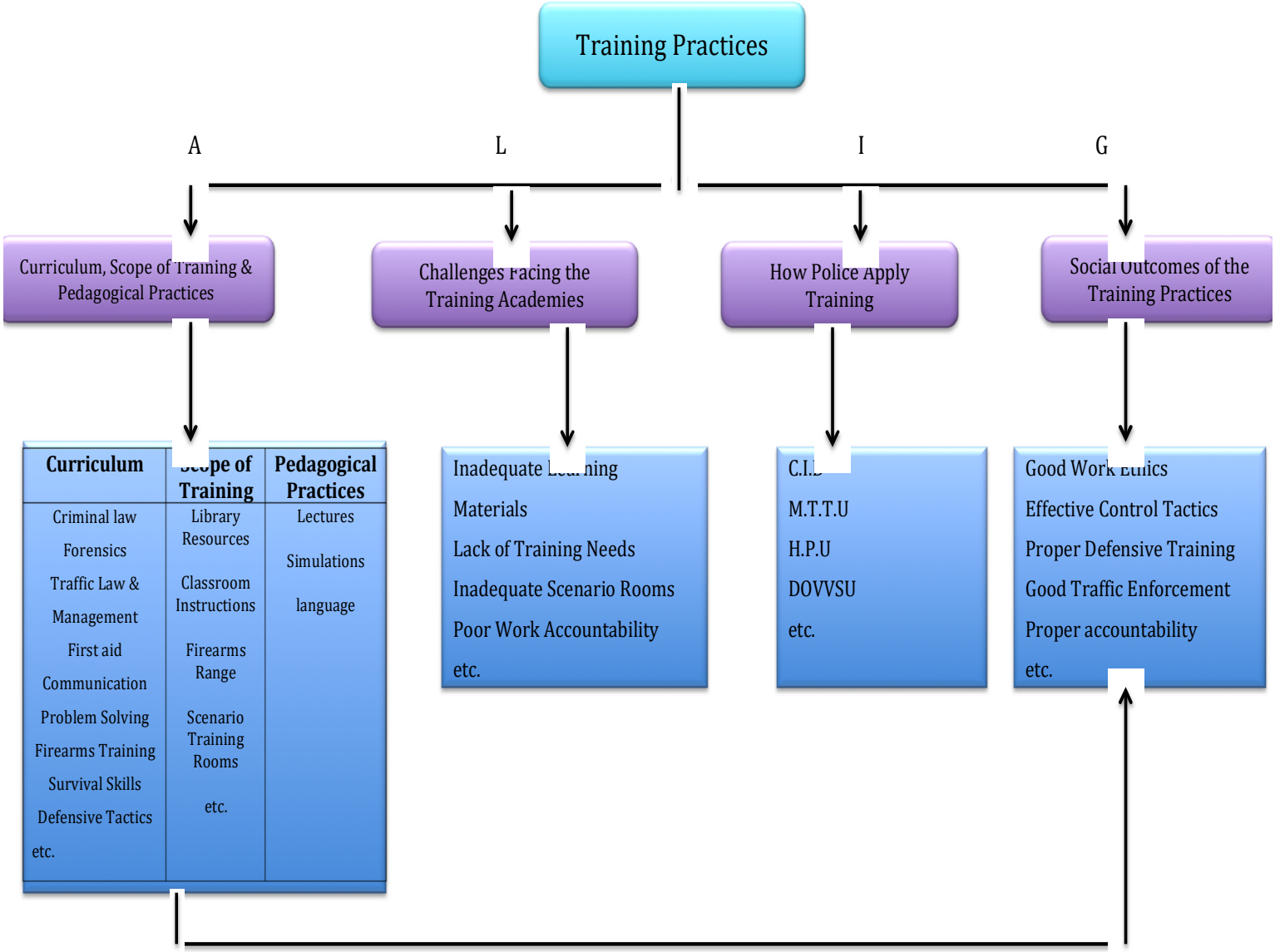

Figure 1: Conceptual Framework

Source: Adapted from Parson AGIL Taxonomy

\section{Discussions}

The literature brought to light that the Ghana Police Service is organized at national level and has a unitary command structure under the Inspector General of Police (IGP). The organisation of the service first started during the 1950s, when the British instituted several changes in the Gold Coast Police Service to modernize, enlarge and better equip the police. The police regions in turn are divided into districts, stations, and posts. The Police Service is composed of General Administration, Criminal Investigations Department (CID), to which Domestic Violence and Victim Support Unit (DOVVSU) are attached, operations department and communication department.

It was also deduced from the literature that recruitment into the police service is conducted at the rank-andfile and the commissioned-officer levels. All recruits must be between eighteen and twenty-five years of age and graduates between twenty-six and thirty-five years and must pass a medical examination, with no criminal record.

The literature revealed that public confidence in the police remains low, and mobs have attacked several police stations due to perceived police inaction, as delay in prosecuting suspects, rumors of collaboration with criminals, and the desire of the public to deal with suspects through instant justice (US Department of State, 2004).

It was also emphasized that after recruitment and selection, the next step is providing appropriate human resources for the organization in training. Training is the process of developing certain qualities in human resources that will help them to be more productive and contribute towards organizational goal and the attainment of such goals. When police are trained very well, they become more productive in the service and that helps them to achieve their goals successfully without any sort of hindrance or fear (Certo, 2003).

The study and review finally found out that police training practices can be assessed in four (4) main ways by using the AGIL taxonomy by Talcott Parsons of Adaptation, Goal Attainment, Integration and Latency.

Adaptation is the knowledge mobilized through the adaptive use of resources. Sociologically, trainees must learn from their curriculum, know the scope of their training and the various pedagogical practices in the police training academies. Trainees using the various resources, tools, gadgets and equipment to facilitate their training are means trainees' or police officers making good use of materials and resources available to them at the police 
training schools. This is what is termed as effective resource utilization. In all of these, trainees learn all the dos and don'ts of the service and know when to apply the right tool appropriately for their core mandates to be achieved appropriately.

It was deduced from the literature that Goal Attainment deals with establishing priorities among system goals and mobilizing system resources for their attainment or the need for all societies to set goals towards which activity is directed (Parsons, 1951 as cited in Schwartz, 2012). To apply this concept by Parsons sociologically, it means that after resources have been secured sufficiently from the environment (police training schools), these resources (knowledge acquired) should then be utilized effectively and efficiently for the goals of the institution be achieved appropriately. Furthermore, the police are expected to work hard in order to meet goals after receiving the necessary training from the police training academies. It was deduced from the literature that the core mandates of the police service as stated in Act 350 of the police service instructions are; the protection of life and property, prevention and detection of crime, apprehension and prosecution of offenders, preservation of peace and good order, and enforcement of all laws, Acts, decrees with which it is directly charged. In all, when all these core mandates of the police service as enshrined in Act 350 are effectively achieved then we can say that they have attained their goals effectively. The sociological application derived from this is that if goals are attained properly and effectively by the police service with the efficient and effective use of resources, a lot of social vices which affects our Political institution, Religious institution, Economy institution, Marriage institution, Education institution, Health institution as well as the mass media will be minimized (PREMEH).

The third concept that was realized under Parson Theory or taxonomy is Integration. With integration, I mean that the various divisions and departments within the Ghana Police Service like the Criminal Investigations Department (CID), the Motor Transport and Traffic Department (MTTD), Domestic Violence and Victim Support Unit (DOVVSU) among others need to be regulated so that a harmonious society can emerge from their interaction for their core mandates and goals to be achieved appropriately (Mensah, 2017). In addition integration also means that trainees should put everything they learnt at the police training school into effective use by applying all the courses they were taught in an appropriate manner to achieve their stated goals. By so doing, a lot of societal problems and disorders we face in our society will be minimized.

Last of Parsons AGIL is Latency. Latency here involves two main things and these are Pattern maintenance and Tension management. Pattern maintenance means establishing proper roles and motives or how to ensure that actors in the social system display the appropriate characteristics in terms of motives, needs and role-playing whereas tension management involves dealing with internal tensions and strains of actors in the social system. Sociologically, it means that the challenges, risks and stresses police officers go through in the course of their day to day duties. For example, the police are being tagged as being corrupt, as being bribed, brutalizing, insubordinate and many other vices that tarnish the image of the police service, it demotivates the police force than motivating them and this creates a very bad societal perception of the service. When this happens the society then loses trust in the police service and therefore finds it difficult to share their problems to police personnel when the need arises.

On the other hand, when these tensions, stresses, risks facing police officers are curtailed or minimized then we are dealing with the internal tensions and the strains of actors in the social system (Mensah, 2017).

\section{Conclusion and Way Forward}

In main, this study made a critical sociological analysis of police training practices using Talcott Parsons AGIL taxonomy. The study focused on how to apply AGIL that is (Adaptation, Goal Attainment, Integration and Latency) in police training practices in Ghana. Using Talcott Parsons' AGIL Taxonomy, the study sought to make a critical sociological analysis of police training practices in Ghana.

First and foremost the literature emphasized on Adaptation on how police trainees and officers can become adaptive to their environment by using resources at their disposal effectively and efficiently to attain organizational goals. It was concluded that variables like police curriculum, their scope of training and their pedagogical practices can only be applied and assessed by using Talcott Parsons AGIL theory of Adaptation. It is therefore recommended that the government through the Ministry of Interior and other stake- holders of the police service must help to provide the needed infrastructure, good facilities, training materials and enough funds to the police training academies to help improve upon the quality of service delivery and to beef up their scope of training and the pedagogy used (Mensah, 2018).

Secondly, the literature highlighted on Goal Attainment as part of Talcott Parsons AGIL taxonomy. It was deduced from the literature that the core mandates of the police service as stated in Act 350 of the police service instructions are; the protection of life and property, prevention and detection of crime, apprehension and prosecution of offenders, preservation of peace and good order, and enforcement of all laws, Acts, decrees with which it is directly charged. These are the goals our police service aims to achieve. Therefore it was concluded that after police personnel has adapted meaningfully to the country's resources, they need to work up to their best to achieve their goals effectively and efficiently. It is therefore recommended that for the police service to achieve their goals appropriately, the government and the other stakeholders, through parliament, must help to enact a law 
or device a code of conduct that will reduce or eliminate political interference during recruits' selection period. This will help produce quality and deserving graduates from the police service who will deliver expectably.

Furthermore, the study well applied Integration to police training practices. Here, it was concluded that in order for the police service as an institution to achieve their goals appropriately, the various units and departments in the police service should harmoniously work together. When these happens police can easily achieve their core objectives hence minimizing petty crimes and social vices in our Political, Religion, Economy, Marriage, Education and Health institutions (PREMEH). It is therefore recommended that the Government, the Ministry of Interior and the Police service must see themselves as one body and not separate bodies working together to achieve a collective goal. Same thing applies to the various units and departments in the police service. As part of the recommendations, the three major stakeholders that is the Government, the Ministry of Interior and the Police service administration must encourage and motivate the authorities in the various police training institutions as well as the police service in general for the professional ways in which they apply their training skills in maintaining law and order in the country.

Finally, the study looked at Latency as the final concept in Parson's AGIL taxonomy. With Latency, the literature brought to light and concluded that the police go through challenges, stresses, risk and tensions in the course of delivering their duties. It is therefore recommended that the government, in collaboration with the Ghana Police administration, and the Ministry of Interior must improve upon the level of motivation and salary packages of the police service to make it more interesting and attractive to the youth which will in turn keep them in the police force to help maintain law and order in the country (Mensah, 2019).

\section{REFERENCES}

Adarkwa, K. K. (2001). Social and economic infrastructure for rapid growth and sustainable development in Ghana. Institute of Statistical, Social \& Economic Research, University of Ghana.

Asare-Bediako, K. (2002). Professional skills in human resource management. Accra: Kasbed Ltd.

Atuguba, R. (2007). The Ghana Police Service (GPS): A Practical Agenda For Reform. Institute of Economic Affairs. Policy Analysis, 3(1).

Bissoondoyal-Bheenick, E., Brooks, R., \& Yip, A. Y. (2006). Determinants of sovereign ratings: A comparison of case-based reasoning and ordered probit approaches. Global Finance Journal, 17(1), 136-154.

Certo, S. C. (2003). Modern management: Adding digital focus. New York: Prentice Hall.

Cole, R. A. (2000). Issues in Web-based pedagogy: A critical primer. Greenwood Publishing Group. Retrieved from

https://books.google.com/books?hl=en\&lr=\&id=Wik2wRC6bksC\&oi=fnd\&pg=PR9\&dq=+Cole+(2000)+Is sues + in + Webbased + pedagogy: $+A+$ critical + primer\&ots $=7$ PBgkt4v0M\&sig $=3 \mathrm{jKJe} 02 \mathrm{QZ} 3 \mathrm{~W} 2 \mathrm{o} 5 \mathrm{bclz} 9 \mathrm{kPuD}$ $\mathrm{PkU}$

Corston, J. (2007). The Coston report. London: Home Office.

Currie, J. (2004). The take up of social benefits. National Bureau of Economic Research. Retrieved from http://www.nber.org/papers/w10488

De Cieri, H., \& Kramar, R. (2003). Human Resource Management in Australia: Strategy.

De Silva, S. (1997). The changing focus of industrial relations and human resource management. International Labour Organisation Publication.

Duah, A. I. (1995). Some African voices of our time. Accra: Anansesem Publications.

Fleck, S. J., \& Kraemer, W. J. (2004). Resistance training and exercise prescription. Designing resistance training programs. Champaign: Human Kinetics, 81-179.

Garriga, E., \& Melé, D. (2004). Corporate social responsibility theories: Mapping the territory. Journal of Business Ethics, 53(1), 51-71.

(Ghana Police Service. (2011). Annual report.

Library of Congress Country Studies. (1994).

Mensah, R. O. (2019). Social outcomes of training practices in the Ghana Police Service. Research on Humanities and Social Sciences, 9, 69-82.

Mensah, R. O. (2018). Assessment of training practices in the Ghana Police Service. Journal of Law, Policy and Globalization, 79, 265-273.

Mensah, R. O. (2017). Assessment of training Practices in the Ghana Police Service. Unpublished master's thesis, University of Cape Coast, Cape Coast.

Metcalf, H., Walling, A. and Fogarty, M. (1994). Individual commitment to learning: Employers attitudes. London: Employment Department Research Series.

Osei. (2008). The Ghana Police Service www.ghanaweb.com

Parsons, T. (1961). Theories of society. Free Press of Glencoe.

Parsons, T. (1951). Social structure and dynamic process: The case of modern medical practice. Retrieved from https://repository.library.george town.edu/handle/10822/762066 
Pokoo-Aikins, J. B. (2009). The police in Ghana, 1939-1999. Pokoo-Aikins.

Schwartz, S. H. (2012). An overview of the Schwartz theory of basic values. Online Readings in Psychology and Culture, 2(1), 11.

US Department of State. (2004).

Winslow, D. (2011). The Gentlemen's Hour: A Novel. Simon and Schuster. Retrieved from https://books.google.com/books?hl=en\&lr=\&id=417smRrlrYC\&oi=fnd\&pg=PA2\&dq=(Winslow, +2011$)+p$ olice+stuff\&ots $=$ RaRXsESJeK\&sig=KwfFsoiacgSXshd3oK6URyyvD6Y 